\title{
Correction to: Sample preparation of formalin-fixed paraffin-embedded tissue sections for MALDI-mass spectrometry imaging
}

\author{
Juliane Hermann $^{1} \cdot$ Heidi Noels ${ }^{1} \cdot$ Wendy Theelen $^{1} \cdot$ Michaela Lellig $^{1} \cdot$ Setareh Orth-Alampour ${ }^{1} \cdot$ Peter Boor $^{2}$. \\ Vera Jankowski ${ }^{1}$. Joachim Jankowski ${ }^{1,3}$
}

Published online: 18 March 2021

(C) Springer-Verlag GmbH Germany, part of Springer Nature 2021

\section{Correction to: Analytical and Bioanalytical Chemistry: https://doi.org/10.1007/s00216-019-02296-x}

The authors would like to call the reader's attention to the fact that, unfortunately, there was a mistake regarding the author contributions of this manuscript; please find the correct information below:

J.H. designed and wrote the original draft. J.J., H.N. and V.J. designed and guided the research. J.H. and M.L. performed and J.H. as well as V.J. analyzed the experiments. J.H. wrote the manuscript. S.O.-A., W.T. and P.B. provided tissue samples. All authors reviewed and approved the manuscript.

Publisher's note Springer Nature remains neutral with regard to jurisdictional claims in published maps and institutional affiliations.

The online version of the original article can be found at https://oi.org/ 10.1007/s00216-019-02296-x

Joachim Jankowski

jjankowski@ukaachen.de

1 Institute for Molecular Cardiovascular Research, University Hospital RWTH Aachen, Pauwelsstraße 30, 52074 Aachen, Germany

2 Institute for Pathology, University Hospital RWTH Aachen, Pauwelsstraße 30, 52074 Aachen, Germany

3 School for Cardiovascular Diseases, Maastricht University, Universiteitssingel 50, 6229, ER Maastricht, The Netherlands 